
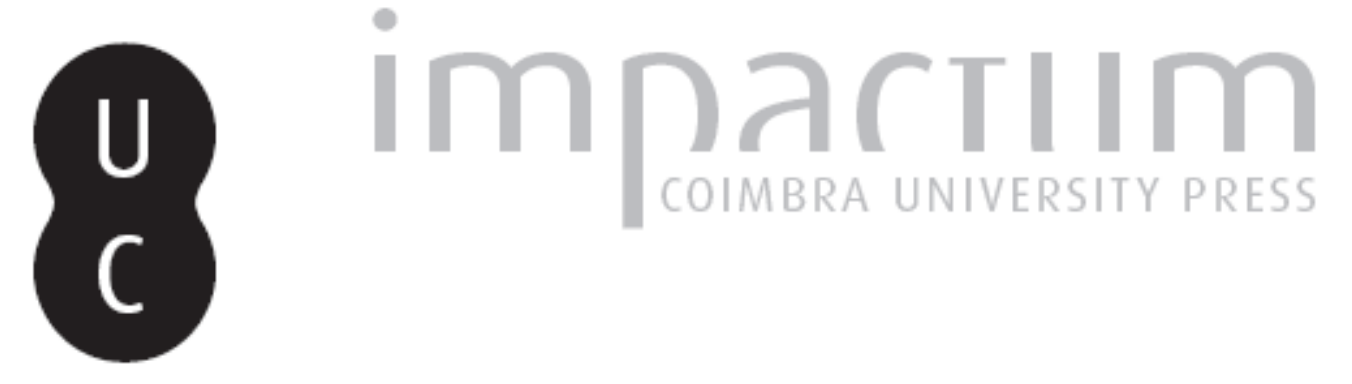

\title{
Spinoza y el arbol de la ciencia del bien y del mal
}
Autor(es):
Beltrán, Miquel
Publicado por: Faculdade de Letras da Universidade de Coimbra, Instituto de Estudos Filosóficos

URL persistente:

URl:http://hdl.handle.net/10316.2/33358

DOI:

DOI:http://dx.doi.org/10.14195/0872-0851_36_4

Accessed : $\quad$ 26-Apr-2023 14:59:25

A navegação consulta e descarregamento dos títulos inseridos nas Bibliotecas Digitais UC Digitalis, UC Pombalina e UC Impactum, pressupõem a aceitação plena e sem reservas dos Termos e Condições de Uso destas Bibliotecas Digitais, disponíveis em https://digitalis.uc.pt/pt-pt/termos.

Conforme exposto nos referidos Termos e Condições de Uso, o descarregamento de títulos de acesso restrito requer uma licença válida de autorização devendo o utilizador aceder ao(s) documento(s) a partir de um endereço de IP da instituição detentora da supramencionada licença.

Ao utilizador é apenas permitido o descarregamento para uso pessoal, pelo que o emprego do(s) título(s) descarregado(s) para outro fim, designadamente comercial, carece de autorização do respetivo autor ou editor da obra.

Na medida em que todas as obras da UC Digitalis se encontram protegidas pelo Código do Direito de Autor e Direitos Conexos e demais legislação aplicável, toda a cópia, parcial ou total, deste documento, nos casos em que é legalmente admitida, deverá conter ou fazer-se acompanhar por este aviso.

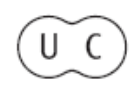




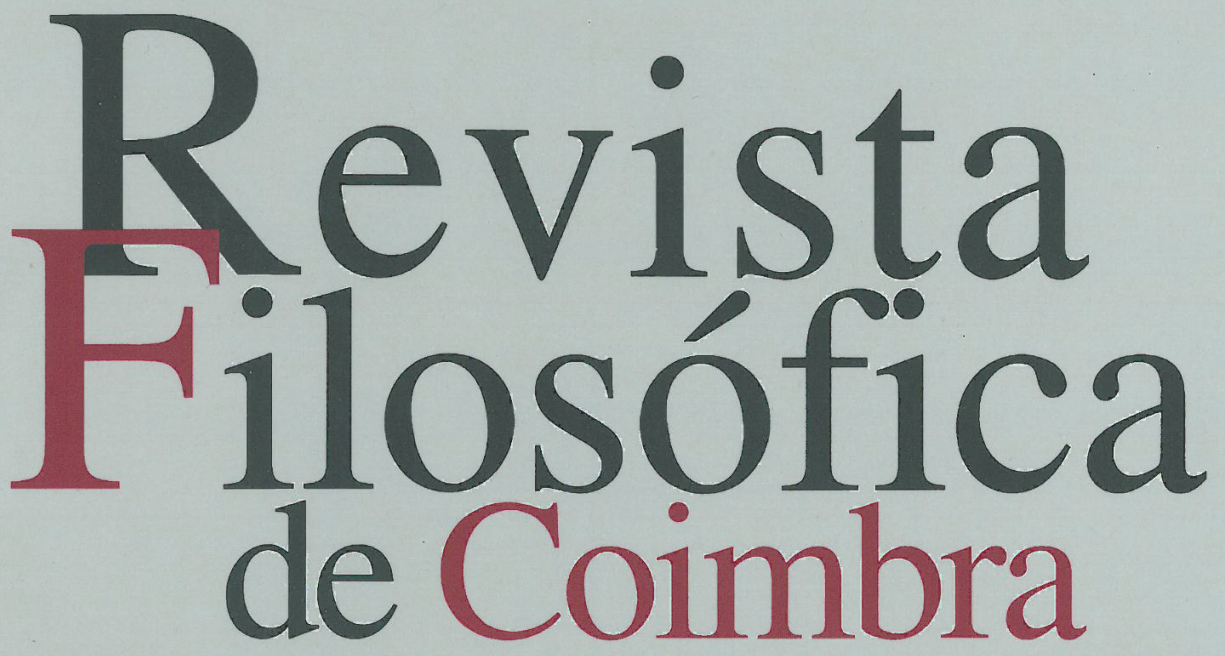

vol.19|n.036 | 2009

Henrique Jales Ribeiro Mario Santiago de Carvalho Edmundo Balsemão Pires Miquel Beltrán Ivo Oliveira 


\title{
SPINOZA Y EL ARBOL DE LA CIENCIA DEL BIEN Y DEL MAL
}

\author{
MIQUEL BELTRÁN*
}

Resumen: En las cartas que Spinoza escribió a Willen van Blijenbergh tratando de resolver algunas de las cuestiones que éste le plantea, acerca de la naturaleza del mal y la caída del primer hombre, hallamos la asombrosa teoría según la cual estaba en la naturaleza del fruto del árbol del bien y del mal, el que si se comiera de él, quien lo hiciere caería en la consideración de las cosas del mundo de modo diferente a como Dios lo hace. Además del estupor que esta afirmación le causa, Blijenbergh no encuentra explicación tampoco para el hecho de que, desde el estado de perfección inicial que se le supone a Adán, su voluntad pudiera mostrarse incapaz de obedecer el mandato divino, pero la razón de ello es que no hay tal mandato, según sostiene Spinoza, sino una advertencia acerca de la nocividad del fruto, que Adán, haciendo caso omiso de la misma-pues no la juzga como tal- decide finalmente probar ${ }^{1}$.

Palabras clave: Adán, Dios, Árbol, Bien, Mal, Fruto Prohibido, Mandato.

\begin{abstract}
In the letters that Spinoza wrote to Willen van Blijenbergh, trying to answer some of the questions the latter presented to him concerning the nature of evil and the fall of Adam, we find the theory that the nature of the fruit was such that anyone who ate from it would see the worldly things in a different way as God does. Besides the astonishment that this affirmation caused him, Blijenbergh doesn't find an explanation for the fact that, from his original state

${ }^{*}$ Universitat de les Illes Balears

${ }^{1}$ La investigación previa a la redacción de este artículo ha sido posible gracias a la participación de su autor, como investigador principal, en el proyecto "Spinoza y la comunidad judía de Amsterdam" (HUM 2006-11482), financiado por el MEC y cofinanciado por el FEDER, como también en el Proyecto de excelencia de la Junta de Andalucía "Maimónides: traducción y estudio" (P06-HUM-01776).
\end{abstract}


of perfection, Adam's will could be unable to obey the divine order, a problem that, according to Spinoza, doesn't exist, because there is no such an order but just and advice concerning the harmfulness of the fruit that Adam, ignoring it for he doesn't judge it as advice- finally decides to eat.

Key Words: Adam, God, Evil, Good, Tree, Forbidden Fruit, Prohibition.

La primera epístola que Willen van Blijenbergh remitía a Spinoza el 12 de Diciembre de 1664 se centraba en la cuestión de cómo, puesto que Dios no sólo ha creado las substancias sino también el movimiento en ellas (lo afirma Spinoza, en efecto, en los Renati Des Cartes Principiorum Philosophiae $^{2}$ y en el apéndice a este obra, el Appendix, continens Cogitata Metaphysica, las obras del filósofo que a la sazón había leído Blijenbergh, comerciante aficionado a los asuntos metafísicos en quien ciertas consideraciones que Spinoza mantiene en dichas páginas suscitaron una incómoda aversión, que le movió a escribirle), podía el filósofo de Ámsterdam no concluir que cualquier tendencia que se dé en la voluntad humana tiene su origen en Dios. Blijenbergh da por sentado que así es, de modo que "de esta aserción parece seguirse necesariamente que: o bien no existe nada malo en el movimiento o voluntad del alma, o bien Dios mismo produce inmediatamente aquel mal"', y aduce el ejemplo de la caída de Adán: "(Así)...el alma de Adán quiere comer del fruto prohibido; (ocurre entonces) que la voluntad de Adán no sólo quiere por influjo de Dios sino que quiere de tal modo. De suerte que o bien aquel acto prohibido a Adán no es ningún mal en sí mismo, en cuanto que Dios no sólo movía su voluntad, sino que la movía de tal modo preciso, o bien el mismo Dios parece efectuar aquello que nosotros llamamos mal"4. Spinoza

${ }^{2}$ Los textos de Spinoza, tras la primera referencia a la obra, en la que se escribirá el título completo, se citarán según la convención internacional. Siglas de las obras: PPC para Renati Des Cartes Principiorum Philosophiae; CM para Appendix, continens Cogitata Metaphysica; Ep para Epistolae, TTP para Tractatus Theologico-Politicus, TP para Tractatus Politicus y E para Ethica ordine geometrico demonstrata (especificamos sólo las obras utilizadas en este trabajo). En cada una de las citas se detallará lo siguiente: tras la abreviatura del título y la ubicación de la cita en la edición canónica de Gebhardt (Spinoza Opera 1924, edición de 1972) -tomo, número(s) de páginas y número(s) de líneas-, indicamos la página en las traducciones castellanas utilizadas, a saber: la de Vidal Peña para la Ethica y las de Atilano Domínguez para el resto de obras, todas publicadas por Alianza Editorial.

${ }^{3}$ EP18, GIV, 82, 35-37. AE 164 (según decíamos, esta primera cita es: Epístola 18, tomo cuarto en la edición de Gebhardt, página 82, líneas 35 a 37. Página 164 en la traducción de Atilano Domínguez, que utilizamos).

4 EP18, GIV, 83, 21-28. AE 164. 
afirmará sin ambages, más adelante, en el Tractatus Theologico-Politicus, lo que a Blijenbergh tanto parece sorprenderle, cuando trata de probar que Adán no puede en modo alguno hacer algo que Dios no quiera: "Si Dios dijo a Adán que ...no quería que comiera del árbol del conocimiento del bien y del mal, sería contradictorio que Adán pudiera comer de dicho árbol, y sería, por tanto, imposible que Adán comiera de él, puesto que aquel decreto debería llevar consigo una necesidad y una verdad eterna. Pero, como la Escritura cuenta que Dios le dio ese precepto a Adán, y que, no obstante, Adán comió del árbol, es necesario afirmar que Dios tan sólo reveló a Adán el mal que necesariamente habría de sobrevenirle si comía (de aquél); pero no le reveló que era necesario que dicho mal le sobreviniese. De ahí que Adán no entendió aquella revelación como una verdad necesaria y eterna, sino como una ley, es decir, como una orden a la que sigue cierto beneficio o perjuicio, no por una necesidad inherente a la naturaleza misma de la acción realizada, sino por la simple voluntad y el mandato absoluto de un príncipe. Por tanto, sólo respecto a Adán y por su defecto de conocimiento, revistió aquella revelación el carácter de una ley y apareció Dios como un legislador o un príncipe"5.

En este fragmento Spinoza parece inferir, del hecho de que Adán efectivamente cayera, un defecto congénito en la capacidad de comprensión del primer hombre con respecto a la naturaleza de lo que Dios le revela, pues Adán entiende que son órdenes acerca de algo que podría ocurrir de modo contingente aquello que en realidad constituyen leyes inflexibles de la naturaleza ${ }^{6}$. Así, ya antes de la caída, en la misma

5 TTP4 ,GIII 63, 12-27.AE 143. Se trata del capítulo 4 del TTP, en el tomo tercero de Gebhardt, página 63, líneas 12-27. Página 143 en la edición de Alianza Editorial. Cf. el artículo de Klever sobre la correspondencia con Blijenbergh (Klever, Wim, 1993, "Blijenbergh's tussing with Evil and Spinoza's Response”, Tijdschrift voor Filosofie 55, 307-329).

${ }^{6}$ La tesis de que el fruto era venenoso en sí mismo, según el orden establecido en la naturaleza, y no debido a que Dios había prohibido a Adán comer de él, tiene ilustres precedentes en el pensamiento judio. Así, Abraam bar Hiia, en su Megillat ha-Megallet, escribe que el árbol causa la caída de Adán debido a su naturaleza y carácter, y no como castigo a su supuesto pecado. Y recurre a este ejemplo: Es como cuando alguien dice: 'No toquéis el fuego porque os quemaréis'. Aquel que osa tocarlo se quema, pero no porque incumpla el mandato o no atienda a la prohibición, sino porque el quemar está en la naturaleza del fuego, si es tocado. Spinoza interpreta, pues, la prohibición, de modo idéntico a como bar Hiia lo había hecho ya en el siglo XII. En la misma obra bar Hiia declara que el mal y las tinieblas no tienen existencia en sí mismos, sino que son la cesación de la vida y de la luz. Sin embargo, y de modo casi paradójico, en su obra cumbre, Hegyon ha-Nefesh, bar Hiia será uno de los pocos exégetas judíos medievales que se enfrentará abiertamente, avant la lettre, a la teoría que Spinoza sostendrá acerca del mal como no-ente, afirmando que Dios es el autor del mismo tanto como del bien. 
incomprensión de la presunta prohibición, se desvela el defecto inherente a la posibilidad de entendimiento, por parte de Adán, del significado del mandato ${ }^{7}$. Y en un capítulo anterior del TTP se lee: "Adán, el primero a quien Dios se reveló, ignoró que Dios es omnipresente y omnisciente, puesto que se escondió de él y se esforzó en excusarse de su pecado ante Dios, como si estuviera ante un hombre. De ahí que también Dios se le reveló según su capacidad, es decir, como si no estuviera en todas partes e ignorara el pecado de Adán y en dónde se encontraba"». Efectivamente, Adán oyó o creyó oír a Dios pasearse por el jardín y llamarle y preguntarle en qué lugar se encontraba; así como supuso después, también erróneamente, que le interrogaba acerca de las razones que le habían movido a comer del árbol que le iba a hacer perder la prerrogativa de ver el mundo en su estado originario. Ambas cosas prueban por sí mismas el distorsionado conocimiento que el primer hombre tuvo de la naturaleza divina. "Adán, pues, no conoció ningún atributo de Dios, excepto que era el hacedor de todas las cosas"9.

En este texto Spinoza parece sostener que no fue como consecuencia del pecado que la capacidad de Adán menguó, y podemos sospechar que así lo creyó por otros textos en los que el filósofo se muestra asombrado de que cayera, desde su primigenia perfección, una naturaleza íntegra como aquélla que la tradición postula que Adán poseyó. Leemos en estas líneas, definitivas, del TP: "Si...el primer hombre tenía potestad tanto para mantenerse en pie como para caer, y si gozaba de sano juicio y de una naturaleza íntegra, ¿cómo pudo suceder que, a ciencia y conciencia, cayera? Claro que dicen que fue engañado por el diablo. Pero ¿quién fue el que engañó al mismo diablo?. ¿Quién, insisto, le volvió tan loco, a él que era la más excelsa de las criaturas inteligentes, como para que quisiera ser mayor que Dios? ¿Es que no se esforzaba, cuanto podía, por conservarse a sí mismo, que tenía una mente sana, y su propio ser? ¿Quién pudo, por otra parte, conseguir que el mismo primer hombre, que era

${ }^{7}$ Que en esencia no es tal. Leemos en Pines: "Fue debido a la flaqueza de la capacidad cognitiva de Adán por lo que la revelación en cuestión se vio transformada en una ley, y Dios....en legislador" (Pines, Schlomo, 1983, "On Spinoza's Conception of Human Freedom and of Good and Evil", en Rotenstreich, Nathan y Schneider, Norma (eds.): Spinoza. His Thought and Work. The Israel Academy of Science and Humanities. Jerusalem, 147-159. La cita está en la página 151). Cf. también Malet, André, 1966, Le Traité Théologico-Politique de Spinoza et la pensée biblique. Les Belles Lettres. Publications de l'Université de Dijon, especialmente las páginas que tratan del origen y la naturaleza del mal en el pensamiento bíblico y en el TTP.

8 TTP2, GIII, 37, 19-28. AE 106.

9 TTP2, GIII, 37, 27-28. AE 106. 
cuerdo y dueño de su voluntad fuera seducido y se dejara embaucar? Pues si tuvo la potestad de usar rectamente su razón, no pudo ser engañado, porque necesariamente se esforzó cuanto pudo en conservar su ser y su alma sana. Por tanto, fue necesario que conservara su mente sana, y no pudo ser engañado. Pero consta por su misma historia que esto es falso. Por consiguiente, hay que confesar que el primer hombre no tuvo la potestad de usar rectamente de la razón, sino que estuvo, como nosotros, sometido a las pasiones"10. Lo más importante es que hay que concluir que Dios se revela a cada uno según su capacidad y de nuevo, que la 'naturaleza íntegra' que permite el conocimiento de los atributos de Dios no se daba en Adán ni siquiera antes de la caída. Una explicación de la razón por la cual aquélla no se daba en él la hallamos en el Escolio de la importantísima Proposición lxviii de la parte cuarta de la Ethica, que reza: "Si los hombres nacieran libres, no formarían, en tanto que siguieran siendo libres, concepto alguno del bien y del mal"11. Puesto que, según la Proposición iv de la misma parte, "es imposible que el hombre no sea una parte de la naturaleza, y que no pueda sufrir otros cambios que los inteligibles en virtud de su sola naturaleza, y de los cuales sea causa adecuada" 12 , la creencia según la cual el hombre nace libre es falsa. Se trata de una hipótesis que sólo podemos concebir en cuanto atendemos a la pura naturaleza humana, o más bien a Dios, en cuanto que es causa de que exista el hombre. Pero ésta sería una abstracción que no atiende a la perfección de Dios como creador de todo aquello que tiene la potencia de producir. En el Escolio de la Proposición lxviii, y aunque Spinoza había denostado contra Maimónides por utilizar la Santa Escritura en la explicitación de materias filosóficas ${ }^{13}$, el de Ámsterdam escribe: "Esto (es decir, la concepción de Dios en cuanto es sólo causa de que exista el hombre) es lo que parece que quiso decir Moisés en la historia del primer hombre. En ella, efectivamente, no se contempla otra potencia de Dios que aquella por virtud de la cual creó al hombre, es decir, una potencia que

10 TP 2/6, GIII, 278, 11-28. AE 87-88. Se trata del capítulo 2 del TP, parte sexta, en el tomo tercero de Gebhardt, p. 278, líneas 11 a 28. Páginas 87 y 88 en la edición de AE, n. 1219.

11 E4P68, GII, 261, 11-13.AE 360. (Parte Cuarta de la Ethica, Proposición 68, en el tomo segundo de Gebhardt, pág. 261, líneas 11 a 13. Página 360 en la edición de Alianza Editorial, n. H 4404).

12 E4P4, GII, 212, 27-30. AE 292.

13 Un artículo eminente en lo concerniente a esta cuestión es el de Harvey, Warren Zev, 1989, "Maimonides and Spinoza on the Knowledge of Good and Evil", Binah 2, 131-146. Cf. Sobre la cuestión del mal en Spinoza el artículo de Campana, Gilberto, 1988, "Il problema del male nel pensiero di Baruch Spinoza", Per la filosofia 5, 51-65. 
tomaba en cuenta sólo la utilidad del hombre; y, en este sentido, narra que Dios prohibió al hombre libre comer del árbol del conocimiento del bien y del mal, y que, tan pronto como comiese de él, al instante temería a la muerte más de lo que desearía vivir. Dice luego que, una vez hallada por el hombre la mujer, que concordaba completamente con su naturaleza, supo que nada podía haber en la naturaleza que le fuera más útil que ella; pero que, nada más creer que los brutos eran semejantes a él, al punto empezó a imitar los efectos de éstos...y a perder su libertad"14. La imposible perfecta esencia racional del primer hombre no puede darse porque Dios lo creó como una parte de la naturaleza, esto es, no atendiendo a una idea del hombre que incluyera las capacidades que imaginamos que puede tener cuando hacemos abstracción de su irrecusable adscripción al mundo natural ${ }^{15}$.

14 E4P68S, GII, 261, 25-31, 262, 1-4. AE 360-361. A propósito de este texto, Wolfson escribió: "(La) exégesis cristiana de la historia de la caída de Adán en el Génesis es indudablemente la fuente directa de la Proposición 68. El escolio parece indicar dicha fuente. La explicación alegórica de la caída....simbolizada por el desliz del hombre desde los dictados de la razón por sucumbir en las trampas de la sensación, cuyo símbolo es Eva...se remonta a Filón" (Wolfson, Harry A. 1934 (edición de1962), The Philosophy of Spinoza. Dos volúmenes, Harvard University Press. La cita está en el segundo volumen, p. 256).Con respecto a esta observación, Pines advierte, sin embargo: "De manera harto sorprendente (Wolfson) no alude a las obvias semejanzas entre la interpretación de Spinoza y la de Maimónides. A este respecto, el hecho de que ambos filósofos piensen...que el conocimiento del bien y del mal es en sí mismo un defecto me parece de gran significación. El hecho de que tanto Maimónides como Spinoza se refieran a que Adán, después de la caída, se vuelve semejante a las bestias debe también ser mencionado, puesto que dicha observación no pudieron extraerla del libro del Génesis" (Pines 1983, p. 150, nota). De Wolfson es útil también para el esclarecimiento de este punto su artículo "Spinoza and Religion", The Menorah Journal 36, 146-167.

${ }^{15}$ En su explicitación de este pasaje, Pines escribe: "La segunda parte del escolio contiene una interpretación de...la caída de Adán. Tiene en común con la interpretación de Maimónides -que es modificada por Spinoza- el supuesto no bíblico de que el conocimiento del bien y del mal marca por sí mismo -sin referencia al castigo que procura- el declive del hombre desde su estado de perfección, que, con acuerdo a Maimónides, consiste en pensar acerca de lo verdadero y lo falso en lugar de hacerlo acerca del bien y del mal....El origen de la comparación instituida por Maimónides entre las nociones de verdad y falsedad, por un lado, y de bien y mal, por el otro, se remonta a un pasaje del De Anima de Aristóteles que trata de la diferencia entre el intelecto teorético y el práctico. Comentadores de Aristóteles, como Temistio, cuyas obras sin duda conocía Maimónides, señalan que lo verdadero es el objeto del intelecto teorético, y lo bueno el del práctico. Juan Filopón observó la superioridad del primer intelecto sobre el segundo" (Pines 1983, p. 149). Sin embargo, "ambos invocan el texto bíblico para imponer su autoridad sobre la idea de que la conciencia moral, en contraste con la intelectual, marca un declinar en la condición humana" (Ravven, Heidi 2001, "The Garden of Eden: Spinoza's Maimonidean Account of the Genealogy of Morals and the Origins of Society", Philosophy \& Theology 13, 3-51. La cita está en la p. 3, nota). 
Todo ello no obsta para que Spinoza se esfuerce en demostrar que tal limitación no introduce el mal en el mundo. En su primera respuesta a Blijenbergh, fechada el 5 de enero de 1665, leemos: "En cuanto puedo colegir por el ejemplo de la voluntad determinada de Adán, parece que entiende por mal la misma voluntad en cuanto que muchos hombres conciben que está determinada de tal modo o que se opone a la prohibición divina"16, para sentenciar que, contrariamente a lo anterior, "por mi parte, no puedo conceder que los pecados y el mal sean algo positivo y mucho menos que exista o suceda algo contra la voluntad de Dios. Por el contrario, no sólo digo que los pecados no son algo positivo, sino incluso que nosotros no podemos decir (a no ser que hablemos impropiamente y al modo humano, como cuando se dice que los hombres ofenden a Dios) que se peca contra Dios" 17 . La distinción entre bien y mal expresa, tal como Naulin advertía, "la perspetiva del hombre que no conoce las cosas según la verdad, es decir...tal como Dios las conoce"18. Esto último lo hace Él considerándolas en sí mismas, y no en relación a cualquier otra cosa, así que la perfección que contiene cada una, tal como es en sí misma -su misma esencia- es la realidad, que Dios, en efecto, conoce. Ocurre con la decisión de Adán que, considerada en sí misma, contiene tanta perfección cuanta realidad expresa. Ni siquiera nosotros, si no la comparásemos con otras decisiones que nos empeñamos en juzgar más perfectas -y que creemos que podríamos esperar de él- veríamos imperfección alguna en que Adán coma del fruto del árbol del bien y del mal. Pues, tal como Naulin advierte, "si la perfección se identifica con la realidad, no tiene contrario alguno, aunque comporta grados que autorizan (la) comparación entre los seres, a cuyo término, convirtiendo (la) diferencia cuantitativa en....cualitativa, llamamos imperfección a lo que en realidad es una menor perfección"19.

Tal como Spinoza lo expresa, la clave de la no-entidad del mal es que "cuanto existe considerado en sí mismo y sin relación a ninguna otra cosa, implica perfección, la cual se extiende en cualquier cosa hasta donde llega la esencia misma de la cosa" 20 , pues la esencia no es sino esa misma perfección (o según leeremos en la Ethica, la propia realidad de la cosa). Así, "esta decisión o voluntad determinada (de Adán de comer del fruto

${ }^{16}$ EP19, GIV, 88, 5-8. AE 167.

${ }^{17}$ Ep19, GIV, 12-17. AE 167-168. Cursiva en el texto holandés, en Gebhardt (se trata del texto original, aunque no autógrafo).

18 Naulin, Paul, "La connaissance du bien et du mal selon Spinoza", Les Études Philosophiques 3, 1969, 359-369. La cita está en la p. 359.

19 Ibid., pp. 362-363.

${ }^{20}$ EP19, GIV, 89, 1-4. AE 168. 
prohibido)...considerada por sí sola, implica tanta perfección, cuanta esencia $^{21}$ expresa" 22 . Dada pues, la incapacidad de la esencia de Adán para entender como orden natural lo que considera un mandato, su perfección se limita a la posibilidad de imaginar las cosas de modo diverso a como en realidad son. Podemos inferir que, según Spinoza, no es imperfección no llegar a entender aquello que nuestra realidad está incapacitada para distinguir, y en efecto, si no comparamos esa incapacidad con la habilidad de otras realidades que eventualmente puedan gozar de un entendimiento más preciso, nada podrá objetarse con respecto a la misma. Por ello, en la decisión de Adán, considerada en sí misma, y no en relación con otra que pudiera mostrar mayor esencia, ninguna imperfección se descubre. Colegimos que los pecados no indican más que inexistencia, no pueden consistir en algo que refleje una esencia o exprese ser, y esto es lo que ocurre en lo que respecta a la decisión de Adán y a su imposible comprensión del mandato.

"Tampoco se puede decir que la voluntad de Adán se oponía a la ley y que, por tanto, era mala, porque era desagradable a Dios. En primer lugar, porque sería poner una gran imperfección en Dios admitir que suceda algo contra su voluntad, o que desee algo que no logra conseguir, o que su naturaleza sea determinada de forma que sienta, como las criaturas, simpatía por unas cosas y antipatía por otras. Y sobre todo, porque eso estaría en contradicción con la naturaleza de la voluntad de Dios; pues, como ella no es distinta de su entendimiento, es igualmente imposible que se haga algo contra su voluntad como contra su entendimiento:...por consiguiente, como la voluntad o decisión de Adán, considerada en sí misma, no era mala ni estaba, propiamente hablando, en contra de la voluntad de Dios, se sigue que Dios puede e incluso....debe ser su causa" 23 . Ocurre que el mal que puede verse en la acción de Adán no es otra cosa que una privación de un estado mejor, que, por efecto de su acción, Adán se ve imposibilitado de alcanzar. "Pero no en cuanto que esa voluntad era mala, ya que el mal que en ella había no era más que la privación de un estado más perfecto que, a causa de esa acción, debió perder Adán"24. Volveremos sobre este último punto más adelante.

Blijenbergh, aun antes de que Spinoza explicite, en la carta 19, su solución al problema del mal declarándolo como un no-ser, una mera privación -haciendo así que éste no precise de concurrencia alguna de la

\footnotetext{
${ }^{21}$ Esencia: 'weesen' en el original holandés; 'realitatis' en la versión latina.

22 Ep19, GIV, 89, 6-8. AE 168.

${ }^{23}$ Ep19, GIV, 90,7-18, 91, 1-4. AE 169.

24 EP19, GIV, 91, 4-7. AE 169. En cursiva en el holandés original.
} 
acción divina (por cuanto no existe más que como carencia)-, le había interrogado a tal respecto, pues en los $\mathrm{CM}^{25}$ Spinoza había ya esbozado tal solución “¿De dónde procedía la voluntad de comer de Adán...? cuestiona Blijenbergh-. Porque, como la voluntad no es algo distinto del alma misma, sino este o aquel movimiento o tendencia del alma, el concurso de Dios le será tan necesario para lo uno como para lo otro. Ahora bien, el concurso de Dios, tal como yo lo entiendo por sus escritos, no consiste sino en determinar una cosa, por su voluntad, de un modo u otro"26. De ahí infiere que Dios determina o aporta un concurso por igual a la voluntad mala en cuanto mala y a la voluntad buena en cuanto buena. Concluye pues Blijenbergh que la voluntad divina es causa primera de la mala voluntad en cuanto tal. Porque Dios, en efecto, decretó, junto con el acto, el modo en que éste se había de realizar, esto es, que Dios no sólo decretó que Adán comiera, sino que lo hiciera contra su mandato. Además,"no puede aplicarse aquí la distinción de los teólogos entre el acto y el mal a él inherente, porque Dios decretó tanto el acto como su modo, es decir, que Dios no sólo decretó que Adán comiese, sino también que comiese necesariamente contra el mandato. De donde parece seguirse, una vez más, o bien que el comer de Adán contra el precepto no es ningún mal, o bien que Dios mismo lo causa" 27 .

Según Spinoza, la privación puede acaso verse como algo malo desde la perspectiva de nuestro entendimiento, pero no desde el divino. Una noción, la de privación, cuyo origen cabe situarlo en el hecho de que definimos de manera única las cosas singulares del mismo género, como ocurría en la tradición judía, y juzguemos que todas ellas son perfectas en tanto que realidades que expresan una esencia, de modo que lo que no está en su mano realizar no tiene entidad, al no formar parte de aquéllas. Dios es la causa de la voluntad de Adán de comer del fruto, pero -como leíamos en una cita anterior- éste la lleva a cabo debido a la privación de un estado mejor 'que Adán debió perder a causa de esa acción' ${ }^{28}$. No se trata, pues de que las perfecciones integren una voluntad que, a la postre, en sí misma no existe, sino que la propia acción demuestra la incapacidad de su autor de realizar otra que, en este caso, creeríamos poder esperar de Adán, sea porque pensemos que debería haber obedecido el mandato -si entendemos que Dios le prohibió comer del fruto-, sea que pensemos

25 Spinoza trata la cuestión en el capítulo VI de los CM titulado 'De la unidad, la verdad, y la bondad'.

${ }^{26}$ EP18, GIV, 83, 30-36. AE 164.

27 EP18, GIV, 84, 28-34. AE 165.

28 Sin embargo, Pines sugiere que Spinoza establece que el conocimiento de las categorías morales es el mismo castigo por la desobediencia de Adán (Cf. Pines 1983). 
que tendría que haber sabido interpretar la advertencia de Aquél por la cual le revelaba que por ley natural el fruto del árbol de la ciencia del bien y del mal le haría conocer, al comer de él, el mundo según categorías morales propias de la imaginación, y dejar de considerar las cosas en sí mismas. Pero la naturaleza de Adán era tal que se demostró incapaz de entender esta revelación divina.

Aquí Spinoza parece conceder a la tradición cristiana que es a causa de la acción acometida por lo que Adán pierde su eventual primigenia perfección (no hay que olvidar, sin embargo, que el texto que examinamos es una epístola privada dirigida a Blijenbergh en la que probablemente hizo concesiones para que éste le comprendiera mejor, ya que hemos visto en otros lugares, en particular en la cita del capítulo II del TP que antes referíamos, que no puede ser así, pues si la naturaleza del primer hombre hubiera sido íntegra, perfecta, su caída habría sido imposible, salvo que, además, la voluntad de Adán es sólo cada una de las acciones que el primer hombre acomete, y lo que a él le ocurre, es, en efecto, consecuencia de las mismas). De nuevo, nuestra malhadada actitud por la cual 'expresamos con una definición única todas las cosas singulares del mismo género...(hace)...que juzg(ue)mos que todas esas cosas son igualmente aptas para la suma perfección que podemos deducir de dicha definición" ${ }^{29}$.Y así, cuando alguna de las cosas del mismo género está privada de la perfección que se sigue de la definición de la cosa, creemos "que se desvía de su naturaleza, cosa que no haríamos, de no haberla puesto bajo aquella definición ni haberle atribuido tal naturaleza" 30 . En esta percepción del género como una invención humana Spinoza sigue la tradición de pensamiento hebreo que abomina de los universales, tal como los largos catálogos de nombres que en la Biblia concretan el paso de una generación a otra, por ejemplo, podrían por sí mismos probar.

Spinoza sabe que dada aquella consideración del mal resulta harto complicado aducir una razón plausible de por qué Dios prohibió a Adán comer del árbol, "cuando él había decidido lo contrario"31. La suya es la siguiente: "La prohibición a Adán consistía simplemente en que Dios reveló (a éste) que el comer del árbol producía la muerte, lo mismo que nos revela a nosotros, por el entendimiento natural, que el veneno es mortífero para nosotros. Y, si me pregunta usted con qué fin se lo reveló, le respondo que para proveerlo de un conocimiento tanto más perfecto.

\footnotetext{
${ }^{29}$ EP19, GIV, 91-8-10. AE 169.

${ }^{30}$ EP19, GIV, 91, 13-16. AE 169-179. En cursiva en el holandés original.

${ }^{31}$ EP19, GIV, 92, 8, AE 170.
} 
Por tanto, preguntar a Dios por qué no le dio también una voluntad más perfecta, es tan inadecuado como interrogarle por qué no dio al círculo todas las propiedades de la esfera" 32 .

En su carta de respuesta, Blijenbergh se rebela contra esta explicación: “¿qué razón hay para que yo deba aceptar la forma de prohibición que usted establece, más bien que la aducida por los profetas, a quienes Dios mismo reveló esa forma de prohibición? Usted dice que su forma de prohibición es más natural y, por lo mismo, más verosímil y acorde con Dios. Pero yo niego todo esto. Pues ni comprendo que Dios nos haya revelado, mediante el entendimiento natural, que el veneno es mortífero, ni veo razón alguna por la que yo deba saber que algo es venenoso, mientras no haya visto ni oído ningún efecto malo del veneno en otros. La experiencia de cada día nos enseña, por el contrario, cuántos hombres, por no conocer el veneno, lo comen sin saberlo y mueren"33.

En su nueva y ya escéptica epístola, en la que declara abiertamente que no cree que pueda llegar a un entendimiento con su interlocutor, Spinoza confiesa "lisa y llanamente...no entend(er) la S. Escritura, aunque le he dedicado algunos años" 34 . No obstante y por el contrario, "cuando he conseguido una demostración sólida, no pueden venir a mi mente ideas que me hagan dudar jamás de ella"35. Así, el filósofo alega que si asiente a algo que el entendimiento le muestra, no puede sospechar que la Escritura tenga fuerzas para contradecirlo, pues "la verdad no contradice a la verdad" 36 .

En la misma epístola el filósofo define la privación no como el acto de privar, "sino tan sólo (como) la pura y simple carencia, que por sí misma no es nada" 37 . Se trata de un modo de pensar que formamos al comparar unas cosas con otras. "Decimos, por ejemplo, que un ciego está

32 EP19, GIV, 93, 15-17, 94, 1-5. AE 171. Cursiva original.En los CM Spinoza arguía ya las razones por las que Dios no puede cambiar sus decretos. Scribano, con respecto a la cuestión tal como se expone en aquella obra, observa: "La posibilidad de una elección (divina) distinta implica una prioridad temporal de Dios con respecto a sus decretos, pero, no habiendo en la eternidad un antes ni un cuando ni un después, ni afección temporal alguna, no puede decirse que Dios existiese previamente a sus decretos de modo que hubiese podido decretar otra cosa" (Scribano, Maria Emanuela 1988, Da Descartes a Spinoza. Percorsi della teologia razionale nel Seicento. Franco Angeli. Milano. La cita está en la p. 101).

${ }^{33}$ EP20, GIV, 120, 36-39, 121, 22-28. AE 188.

${ }^{34}$ EP21, GIV, 126, 24-25. AE 192.

35 EP21, GIV, 126, 25-27. AE 192-193.

36 EP21, GIV, 126, 30. AE 193.

${ }^{37}$ EP21, GIV, 128, 12-13. AE 195. 
privado de la vista porque lo imaginamos fácilmente como vidente, ya surja esta imaginación de compararlo a él con otros que ven o de comparar su estado actual con el anterior, en que veía. Cuando consideramos así a ese hombre, comparando su naturaleza con la de otros o con la suya pasada, afirmamos que la vista pertenece a su naturaleza y por eso decimos que ahora está privado de ella. Pero cuando se considera el decreto de Dios, y su naturaleza, no tenemos más razón para decir que ese hombre está privado de la vista que lo está la piedra, ya que en ese momento es tan contradictorio atribuir la vista a ese hombre como a la piedra" 38 . Y a continuación: "Porque a ese hombre no le pertenece como propio más que lo que le atribuye el entendimiento y la voluntad de Dios"39.

Así, el entendimiento y la voluntad de Dios (que son uno y lo mismo) atribuyeron a Adán una naturaleza que no permitió a éste conocer sus atributos ni atender a su advertencia evitando comer del fruto que Aquél le reveló (según la interpretación spinoziana del mandato) que sería mortífero para él. Y con todo, "el apetito de cosas terrenas de Adán era malo respecto a nuestro entendimiento y no respecto al divino. Pues, aunque Dios conocía el estado pretérito y el presente de Adán, no por ello pensaba que Adán estaba privado del estado pretérito , es decir, que le pertenecía a su naturaleza" 40 . Dios entiende y quiere que a la naturaleza de Adán le pertenezca el no ser capaz de evitar la tentación, aunque le reveló lo que ocurriría si no lo hiciera, y sabía, además, que no lo haría. En caso contrario, "Dios entendería algo contra su voluntad, es decir, contra su propio entendimiento" 41 .

En su siguiente carta Blijenbergh afirma no poder comprender que Dios desee los crímenes del mismo modo en que desea 'lo que usted

${ }^{38} \mathrm{EP} 21, \mathrm{GIV}, 128,15-26 . \mathrm{AE} 195$.

39 EP21, GIV, 128, 26-28. AE 195. En cursiva en el texto latino en el que nos ha llegado la epístola. El original holandés, al que aludirá Blijenbergh en su siguiente carta, se ha perdido. Ravven escribe con respecto a este punto: "Contra Maimónides....Spinoza arguye aquí que Adán no pudo tener 'una mente íntegra' antes de la desobediencia. Aquí Spinoza advierte que la historia bíblica de Adán, más que una especulación contrafáctica, es....una explicitación histórica que da cuenta de cómo la humana es una condición de vulnerabilidad intelectual” (2001, p. 29). Cf. También Berman, Lawrence V., 1980, "Maimonides on the fall of man", Association for Jewish Studies Review 5, 1-15. Pero ni siquiera porque una voluntad o mente íntegra, perfecta, la contradiría la propia acción de comer del árbol, sino porque no existe nada semejante a una voluntad, considerada independientemente de las acciones que se realizan, sino sólo estas mismas acciones, que son, consideradas en sí mismas -sin relación a ninguna otra cosa- perfectas.

40 EP21, GIV, 129, 7-12. AE 196. En cursiva en el texto latino.

${ }^{41}$ EP21, GIV, 129, 11-13. AE 196. 
denomina virtud'. Leemos: "Como la voluntad de Dios da a cada uno la aptitud para su obra, se sigue que de aquellos a quienes menos ha dado exige exactamente igual que de aquellos a quienes ha dado más. Por consiguiente, Dios, considerado en sí mismo...quiere....el deseo del placer y el deseo de la virtud. Y así...Dios quiere exactamente igual el crimen que la virtud, y....es la causa tanto del uno como de la otra. Y, por lo mismo, ambos deben serle igualmente gratos" 42 . Así, Blijenbergh entiende que, según Spinoza, "servir a Dios no es otra cosa que ejecutar las obras que Dios ha querido que realicemos.... ¿qué diferencia existe, entonces, respecto a Dios, entre el servicio de los justos y el de los impíos?...Ambos ejecutan la voluntad de Dios de la misma forma, a saber, según su decreto ..¿qué diferencia puede existir, entonces, entre ambas esencias respecto a Dios?....iqué razones hay, pues, para que los unos, por sus acciones, se hagan más perfectos, y que los otros, sirviendo, se consuman?"43, para concluir que, según Spinoza, "en realidad, no existen errores ni delitos, sino que todo contiene exactamente la esencia que Dios le da, la cual, sea la que sea, siempre incluye perfección" 44 . Parece que, a diferencia de lo que algunos estudiosos han sospechado, Blijenbergh comprendió de modo muy preciso la doctrina spinoziana acerca del mal, sólo que le repugnaba aquello que podía colegirse de ella.

Con gran reticencia Spinoza se decide a escribir una última carta de respuesta a Blijenbergh, y en ella sentencia: "Afirmo...que Dios es absoluta y realmente causa de todas las cosas que tienen esencia, cualesquiera que sean. De forma que si usted puede demostrar que el mal, el error, los crímenes, etc..son algo que expresa una esencia, le concedo sin reservas que Dios es la causa de los crímenes, del mal, del error" ${ }^{45}$...Sin embargo, Spinoza entiende que ha probado que nada de esto expresa una esencia, y el ejemplo que aquí elige es el de Nerón: "El matricidio de Nerón..en cuanto incluía algo positivo, no era un crimen, pues también Orestes realizó la acción externa y tuvo además la tentación de asesinar a su madre y, sin embargo, no es acusado tanto como Nerón..La diferencia es que Nerón se manifiesta, en esa acción, ingrato, inmisericorde...pero esto no expresa una esencia, y Dios no es causa de ello, aunque sí del acto y de la intención de Nerón" ${ }^{46}$. Al igual que en el caso de Adán, la ineptitud de Nerón para entender, que le impulsa al matricidio, no expresa esencia.

\footnotetext{
42 EP22, GIV, 138, 27-38. AE 204-205.

43 EP22, GIV, 139, 23-37. AE 205-206.

44 EP22, GIV, 140, 29-33. AE 206.

45 EP23, GIV, 147, 1-5. AE 210. En cursiva en la carta autógrafa en holandés.

46 EP23, GIV, 147, 8-16. AE 210-211.
} 
Si el pecado de Adán es su incapacidad para conocer los atributos de Dios y para guiarse en su acción por el conocimiento de Aquél, podría suponerse que la superación del pecado se daría a través de la adquisición de tal conocimiento. De acuerdo con Maimónides tal corrección, que conduciría al conocimiento intelectual, es el propósito supremo de la Torá, y Spinoza parece conceder también que el conocimiento intelectual de Dios corregiría la caída de Adán, aunque su terminología le aparta decisivamente de la utilización de la narración de la caída en el Génesis, lo que no obsta para que, como afirma Ravven, "Spinoza (use) la interpretación de la desobediencia de Adán en el jardín del Edén para erigir una defensa bíblica de la vida dedicada a los logros intelectuales como la mejor, la más satisfactoria y virtuosa" 47 . Lo importante es, sin embargo, que ambos -Maimónides y Spinoza- afirman que el hombre que supiera llegar a guiarse sólo por el intelecto sería incapaz del conocimiento del bien y del mal, y que éste consiste, pues, en algo propio de la imaginación, inadecuado. Se trata, este último, de un conocimiento no intelectual que nada tiene que ver con la verdad de la cosa, tal y como en los CM que Blijenbergh leyó ya se postula ${ }^{48}$, consideración expuesta también en la Guía de Perplejos de Maimónides, para quien el bien y el mal sólo se entienden en sentido relativo. Una cosa, considerada por sí sola, no se concibe ni buena ni mala; sólo se dice tal respecto a otra, según que resulte o no útil para lograr algo que se ama. De ahí que la misma cosa se puede argüir, al mismo tiempo, buena o mala, en sentido distinto. En su defensa de esta idea, Spinoza recurre de nuevo al Testamento: "Así, por ejemplo, el consejo dado por Aquitofel a Absalón se dice bueno en la Sagrada Escritura; sin embargo, era pésimo para David, puesto que maquinaba su muerte. Además, hay otras muchas cosas que son buenas, pero no para todos; y así, la salvación es buena para los hombres, y, en cambio, para los brutos y las plantas, no es buena ni mala, porque no tiene nada que ver con ellos" 49 .

Harvey se pregunta: "¿no hay nada pues en el mundo que convenga al propósito o sea útil (sin apelación) a nuestro hipotético hombre guiado por el intelecto?". ${ }^{50} \mathrm{La}$ verdad parece conformarse a su propósito y ser

${ }^{47}$ Ravven 2001, p. 3.

48 CM1/6, GI, 247,23-26. AE 246. Se trata de la parte primera de los CM, capítulo 6, pág. 247, líneas 23 a 26. Página 246 en la edición de AE, n. 1325:”El bien y el mal sólo se dicen en sentido relativo. Una cosa, considerada por sí sola, no se dice ni buena ni mala". Cursiva en el original.

${ }^{49}$ CM1/6, GI, 247, 26-32.AE 246.

${ }^{50}$ Harvey 1989, p. 135. Cf. También el interesante artículo de Blumberg, Harry, 1972, "Theories of Evil in Medieval Jewish Philosophy", Hebrew Union College Annual 43, 149-168. 
útil para él; así, cuanto conduzca a la verdad es bien, y el bien es la verdad. Pero, en la medida en que las nociones de bien y mal se identificarían así con las de verdad y falsedad, se convertirían, como Harvey sospecha, en superfluas de manera inmediata. Por esta razón tanto Maimónides como Spinoza advierten que los términos 'bien' y 'mal' se tornan en completamente carentes de sentido cuando el hombre adquiere el conocimiento de lo necesario. En tanto que el hombre sigue sumido en la concepción de las cosas como probables, inciertas, en ese sentido le cabe calificarlas a través de la inadecuada percepción que la imaginación le procura de ellas, como buenas o malas. Para el hombre guiado por el intelecto, sin embargo, 'bien' y 'mal' serían no sólo conceptos subjetivos, sino conceptos completamente carentes de significado. Por lo demás, aquel perfecto conocimiento de Dios sería el supremo bien aunque para el hombre que lo posee concebir esa idea de bien -como contrapuesto al mal- no hubiera sido posible. Pero, y aunque no "aluden a nada positivo en las cosas....ni son otra cosa que modos de pensar, o sea, nociones que formamos, a partir de la comparación de las cosas entre sí, debemos conservar esos vocablos ('bien' y 'mal').... Pues, ya que deseamos formar una idea de hombre que sea como un modelo ideal de la naturaleza humana, para tenerlo a la vista, nos será útil conservar esos vocablos en el sentido que he dicho. Así pues, entenderé en adelante por 'bueno' aquello que sabemos con certeza ser un medio para acercarnos cada vez más al modelo ideal de naturaleza humana que nos proponemos" 51 .El conocimiento intuitivo de Dios y el acercamiento a la verdad pueden ser llamados buenos en la medida en que sabemos con certeza que nos son útiles. Con todo, y según las palabras contenidas en los CM, ese bien sería relativo, porque lo sería para el hombre pero presumiblemente no para las plantas o los animales, como según la cita referida tampoco lo es para estos últimos el salvarse.

Puesto que para Spinoza la última adquisición intelectual es el conocimiento de lo real, de lo verdadero, el término 'bien' denota el conocimiento de la existencia, y también esta misma existencia, la absoluta verdad $^{52}$. Verdad se convierte en la Ethica en un término metafísico (pero esto ocurría también en Maimónides) y ello como consecuencia de un monoteísmo férreo. El Dios que conoce, es conocido y es el mismo conocimiento tal como lo estipula El libro del conocimiento (Yesodé ha-Torah II, 10 del Misné Torá maimonídeo), se convierte en Spinoza en

${ }^{51}$ E4I, GII, 208, 8-20. AE 286-287.

52 Tal como Demos observó, para Spinoza "el valor como distinto de la realidad no tiene un significado genuino" (Demos, Raphael, 1933, "Spinoza's Doctrine of Privation", Philosophy 8, 155-166. La cita está en la p. 155). 
el Dios que produce (Natura Naturans), uno de cuyos modos infinitos es el intelecto que lo piensa. Para Maimónides, el verso repetido en el Génesis 'Y Dios vio lo que había hecho, y vio que era bueno', prueba que la palabra 'bueno' está para lo que existe en realidad, y según la terminología spinoziana, realidad y perfección serán una y la misma cosa. De nuevo, los términos 'perfección' e 'imperfección' son modos de pensar (y por lo tanto, superfluos), pues toda realidad, concebida en sí misma, sin compararla con otras distintas, es, sin apelación, verdadera, (y en la misma medida, buena). Por todo lo anterior, Dios, que conoce a la perfección todas las cosas, es incapaz de discernir entre el bien y el mal. Por lo tanto el engaño de la serpiente a la mujer se basa en la mentira. No sólo trata de convencer a Eva de que desobedezca a Dios, sino que la engaña tout court al decirle que será (al igual que Adán) como Él si come del fruto. Es sorprendente que las interpretaciones del episodio no contemplen por lo general la idea de que la serpiente mienta en este sentido, y que se arguya que en efecto Adán y Eva adquieren el conocimiento que Dios poseía también. Cierto es que resulta conflictivo el pasaje en el que se lee que Dios, tras vestir al hombre y su mujer, se dijo: "He ahí al hombre hecho como uno de nosotros, conocedor del bien y del mal; que no vaya ahora a tender su mano al árbol de la vida, y comiendo de él, viva para siempre" 53 . En este sentido, Rosenberg observa: "Es como si Dios estuviera de acuerdo con las palabras de la serpiente. Pero, según entiendo que hay que leer a Maimónides, hay aquí ironía por parte de Dios. Dios pronuncia estas palabras de forma irónica, como buscando el ridículo. Esta idea era ya familiar a los comentadores bíblicos de la Edad Media, y dos de ellos, R. Hillel de Verona y Don Isaac Abravanel, lo expresaron en sus escritos. La clave del relato es que la facultad imaginativa engaña al hombre prometiéndole algo que ni quiere ni puede cumplir" 54 .

Tal como Harvey sentencia, en Spinoza, epistemología y metafísica se reflejan la una en la otra como un par de espejos. Un reflejo que tiene su origen, según el estudioso, en el extremo monoteísmo por el cual -lo referíamos- Dios conoce, es conocido, y es el mismo conocimiento, de modo que todo conocimiento verdadero lo es de Dios, en dos sentidos: Dios como sujeto y Dios como objeto. Él como la realidad tal cual es en sí misma, y como Aquél que conociéndola, se conoce. Y si para Maimónides la palabra 'bueno', con la cual Dios describe lo que crea,

53 Génesis 3:22.

54 Rosenberg, Sâlom, 1996, El bien y el mal en el pensamiento judío. Riopiedras ediciones. Barcelona, p. 77. 
denota la realidad misma, la equivalencia entre realidad y perfección, en la obra capital de Spinoza, responde a idéntico criterio. Creer que una decisión es imperfecta comporta un conocimiento inadecuado de su realidad, y el imperativo filosófico de la libertad humana no se corresponde con la condición original de Adán. En este sentido Pines sugería como apuntábamos- que la adquisición de las categorías morales es el castigo a Adán por comer del fruto, pero sería mejor decir, es la consecuencia de que éste resulte, por su naturaleza, mortífero para la verdadera comprensión del mundo en aquél. La caída sería una consecuencia necesaria de comer del árbol del conocimiento del bien y del mal. Y la naturaleza de Adán estaba constituida de tal modo que no supo entender que Dios no prohibía, sino que lo advertía de cómo operaba una ley natural, pues, tal como Spinoza sostiene en el TTP, "las afirmaciones y negaciones de Dios implican siempre una necesidad o una verdad eterna" 55 .

55 TTP4, GIII, 63, 10-12. AE 143. 